in relative humidity. This switching mechanism also is adaptable for giving rapid and discrete changes in temperature.

It is designed to operate at test-chamber temperatures above $0^{\circ} \mathrm{C}$, but may readily be used at temperatures as low as $-40^{\circ} \mathrm{C}$. The low temperatures are achieved, however, at some sacrifice of the maximum attainable relative humidity. For most of the test-chamber temperature range, practically any desired relative humidity may be produced by the apparatus.

Independent checks on the performance of the ap- paratus by means of the gravimetric method of moisture determination and the psychrometric method show an average agreement in relative humidity of 1.2 percent as measured and as given by the apparatus, eq 2.

The author gratefully acknowledges the assistance of R. A. Baum of the Shop Division in the construction of the apparatus and of E. T. Woolard in the experimental work.

Washington, August 14, 1950.

\title{
An Improved Apparatus for Determining Moisture in Rubber by Distillation with Toluene
}

\author{
By Max Tryon
}

\begin{abstract}
An improved apparatus has been developed for the determination of water in rubber by distillation with toluene. The volume of the water collected is measured in a graduated capillary tube, which allows more precise measurement than the tapered tube formerly used. The interior of the trap and condenser is coated with a water-repellent silicone polymer to prevent water droplets from adhering to the walls and to improve the accuracy. This paper describes the construction of the apparatus and a procedure for coating its interior with the silicone polymer. A method for calibration of the trap is included in a general procedure for use of the equipment.
\end{abstract}

\section{Introduction}

The water content of certain organic materials can be determined by a method that involves the formation of an azeotrope of an immiscible organic liquid with the water, distillation of the azeotrope, and separation of the water as a separate phase. The volume of water is then measured by the use of a graduated container.

For this purpose there are several devices commercially available for the collection and separation of water distilled with a liquid of low density, such as toluene. Since the time of Dean and Stark [1] ${ }^{1}$ there have been a large number of refinements and special applications similar to their original apparatus [2 to 9]. These refinements are essentially attempts to overcome the following shortcomings of the original design. First, there is a tendency for water to adhere to parts of the apparatus rather than to collect in the graduated portion. Second, there is a lack of precision of reading the volume of water collected due to the dimensions and shape of the graduated container. Third, sharp separation of the immiscible liquid and water does not always occur in apparatus with narrow water-collecting tubes, because the immiscible liquid tends to be trapped in the tube by the water. Fourth, the apparatus must be meticulously clean or the water will entrap the immiscible liquid and will not properly fill the measuring tube, regardless of the shape or dimensions of the tube.

\footnotetext{
1 Figures in brackets indicate the literature references at the end of this paper.
}

Subsequent modifications and refinements of the original apparatus have overcome some of these objections to varying degrees. The apparatus described in this paper, however, answers all these objections satisfactorily and also offers a few more advantages.

The procedure and apparatus described in this paper was originally devised in 1947 to determine small amounts of water (about $1 \%$ by weight) present in certain types of synthetic rubber $[10,11]$ that could not be analysed with procedures standard at that time. As a result, this procedure has been accepted as a referee method for determining moisture in all types of synthetic rubbers by the Subcommittee on Test Methods, Reconstruction Finance Corp., Office of Rubber Reserve.

It is felt that this apparatus supplies the need for a rapid, simple, precise method for determining small amounts of water in materials on a routine production basis and furnishes a valuable tool for research.

\section{Description of Apparatus}

The apparatus is shown schematically in figure 1. The distilling flask, $A$, contains the sample and toluene. This flask is connected to the collecting trap, $T$, by a $24 / 40$ standard taper joint lubricated with silicone stopcock grease. A West condenser equipped with a drip tip is connected to the trap by means of a 24/40 standard taper joint, also lubricated with silicone grease. The tapered portion of the trap 


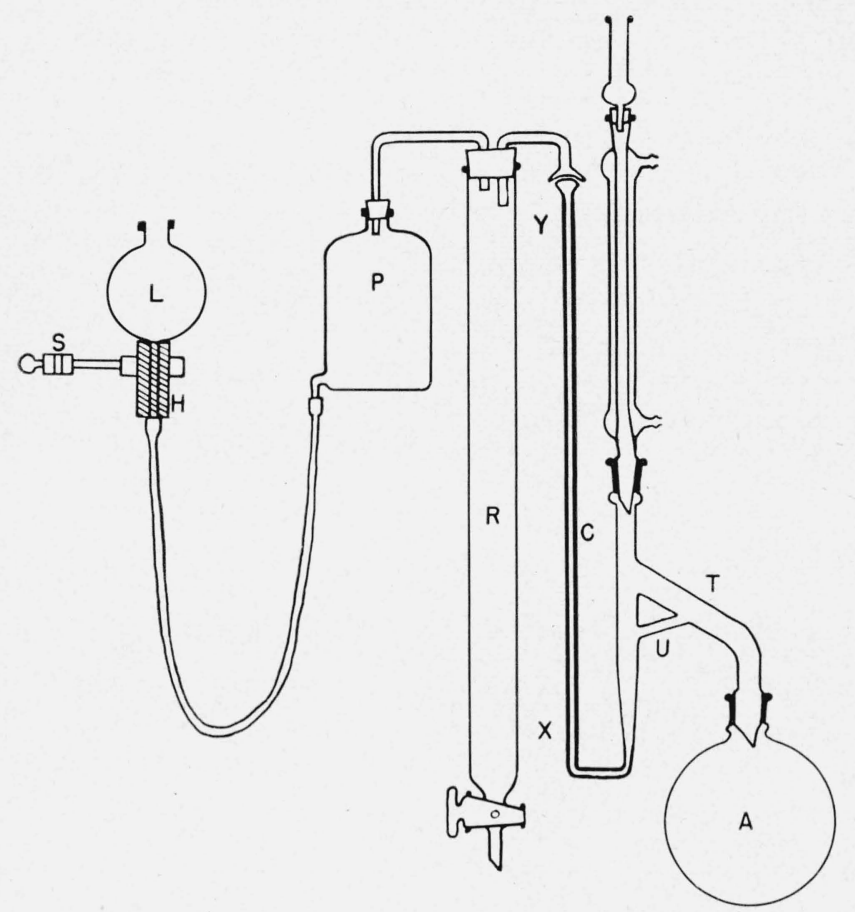

Figure 1. Distillation apparatus.

has a volume of about $10 \mathrm{ml}$ below the overflow tube, $U$. The overflow tube slopes upward from the tapered portion and so prevents drops of water, falling from the condenser tip, from returning to the distilling flask. A capillary tube, $C, 56 \mathrm{~cm}$ long and of about $1.5-\mathrm{ml}$ volume is sealed to the bottom of the tapered portion of the trap. This capillary is graduated at $1-\mathrm{mm}$ intervals between the points $X$ and $Y$ (50-cm length) and has a $12 / 3$ ball joint at the top end. This joint, lubricated with silicone grease, serves to connect the capillary to a waste receiver, $R$, which has a drain stopcock at the bottom. The waste receiver is connected by rubber tubing to a bottle of water, $P$, which is in turn connected by rubber tubing to a leveling bulb, $L$. The leveling bulb has both a coarse and a fine adjustment. Raising or lowering the clamp, $S$, affords the coarse adjustment, and the threaded tube, $H$, allows the fine adjustment. Thermometer reading lenses prove very useful for reading the scale on the graduated capillary tube.

The capillary tube, the trap, and the condenser are coated with a thin film of silicone polymer to prevent water droplets from adhering to the walls of the apparatus. The effect of this coating is to reverse the usual water-glass meniscus, and the result is a mercury-type meniscus that is easily seen in the capillary. The silicone coating is applied by pouring a solution, $5 \mathrm{ml}$ of mixed methylchlorosilanes (Drifilm) dissolved in $100 \mathrm{ml}$ of dry toluene, into the clean air-dried apparatus and allowing it to stand in contact approximately $15 \mathrm{~min}$ before pouring out the excess solution. It is important that the glassware be air-dry and not oven-dry, as a very thin layer of adsorbed water on the glass surface is essen- tial to form the coating [14]. Caution: It is recommended that this operation be carried out in a hood, as the methyl chlorosilanes are toxic, flammable, and corrosive. The apparatus is then air-dried and heated overnight in an oven at $105^{\circ} \mathrm{C}$. The apparatus may be used indefinitely and may even be rinsed with acid-dichromate cleaning solution without disturbing the film or the calibration of the capillary. However, the film may be removed by soaking the equipment for 10 to $15 \mathrm{~min}$ in alcoholic potassium hydroxide.

The distilling flask may be heated by any suitable heat source, but an electric enveloping heater is recommended for best control of the distillation.

\section{Operation of Apparatus}

\section{Calibration}

The capillary is calibrated by adding, progressively, weighed increments of water to the tapered portion of the trap, which has been filled previously with dry toluene up to the overflow tube. After each increment has been added, the water in the trap is raised up into the graduated capillary by lowering the leveling bulb. The fine adjustment affords a simple and quick method for adjusting the bottom of the water column to a zero point on the capillary. The height of the column is noted and the leveling bulb raised to return the water to the tapered portion of the trap. Another weighed increment of water is added and the process repeated. The size and number of the increments to be measured depends on the accuracy and precision desired.

Because toluene is present in the trap, the water column is confined between two columns of toluene while being measured. This prevents evaporation loss and also aids in obtaining a sharp mercury-type meniscus at both ends of the water column. Varying the weight of the water added and measuring the column lengths obtained allows precise calibration of the capillary. If the capillary is uniform, a simple length-to-weight factor is all that is required. However, if the capillary is nonuniform, a simple graphical calibration curve is readily made from such measurements.

\section{Distillation of Sample}

The sample is weighed to the desired accuracy and placed in the distilling flask with a sufficient amount of toluene to keep the sample covered. The toluene is dried by passing it through a column of activated silica gel. The trap is filled up to the overflow tube with dry toluene and the distilling flask heated slowly until liquid begins to drop from the tip of the condenser. The distillation is continued at the proper rate, depending on the type of sample used, until no more water droplets appear in the distillate dropping into the large part of the trap. Five milliliters of dry toluene is poured in the top of the condenser to wash any water adhering to the condenser down into the trap. The heater is then turned off and the water in the trap allowed to cool to room 
temperature, or a beaker with cool water may be lifted around the trap to aid in adjusting the temperature to a predetermined value, dependent on the temperature of the calibration procedure. After cooling, the leveling bulb is lowered to draw the distilled water into the capillary and to adjust the bottom of the water column to the zero point used as a reference in the calibration of the graduated capillary. The length of the water column is read, and then the leveling bulb is lowered further to draw the water and toluene in the trap into the waste receiver. The trap is again filled up to the overflow tube with dry toluene, and the distilling flask is replaced with another flask containing a sample and toluene. This procedure allows another sample to be run almost immediately. Cleaning the trap at intervals by flushing with toluene is accomplished by pouring toluene in the trap through the condenser and lowering the leveling bulb to draw the solvent through the capillary into the waste receiver. The stopcock on the bottom of the waste receiver allows removal of the accumulation of water and toluêne.

\section{Accuracy and Precision}

Several experiments, designed for statistical analysis, in which a number of possible variables were studied, were used to evaluate the method. The known samples were prepared in batches by taking a 200-g batch of GR-S-10 synthetic rubber and milling it for approximately $5 \mathrm{~min}$., after which it was sheeted out at a setting of 0.02 -in. distance between the mill rolls and then placed in a vacuum oven at $90^{\circ} \mathrm{C}$ for $4 \mathrm{hrs}$. After the rubber was dried, it was stored in a desiccator overnight. The rubber was then weighed to the nearest milligram and passed through the mill at a 0.02 -in. setting several times, taking care that no rubber was lost from the mill. The sample was reweighed to check for loss of rubber. After the rubber was checked for loss in weight, it was banded on the mill, and two $10-\mathrm{ml}$ portions of distilled water were milled into the sample and the mixture thoroughly blended. The sample was next removed from the mill and placed on an electrically grounded sheet of aluminum to cool and discharge the static charge formed during the milling operation. After approximately $10 \mathrm{~min}$., the rubber was weighed. A portion of the rubber was cut into pieces small enough to pass through the opening of the distilling flask and placed as quickly as possible in a weighed tin with an air-tight cover. The remaining portion of the wet rubber was reweighed and stored in an airtight container. The tin containing the sample was weighed and the sample then removed and placed in the flask containing the toluene. This procedure gave several checks for the weight of the sample, the moisture content by weight, and the possible loss of moisture during handling. Under these conditions the loss of moisture during handling was found to be less than $1 \mathrm{mg}$.

The data shown in table 1 [11], after statistical analysis, indicated that there was no significant de- pendence of the precision and accuracy, within the limits of this experiment, on the size of the sample or on the time of distillation after the water droplets cease to appear in the distillate. The slope and intercept of each curve shown in figures 2,3 , and 4 indicate

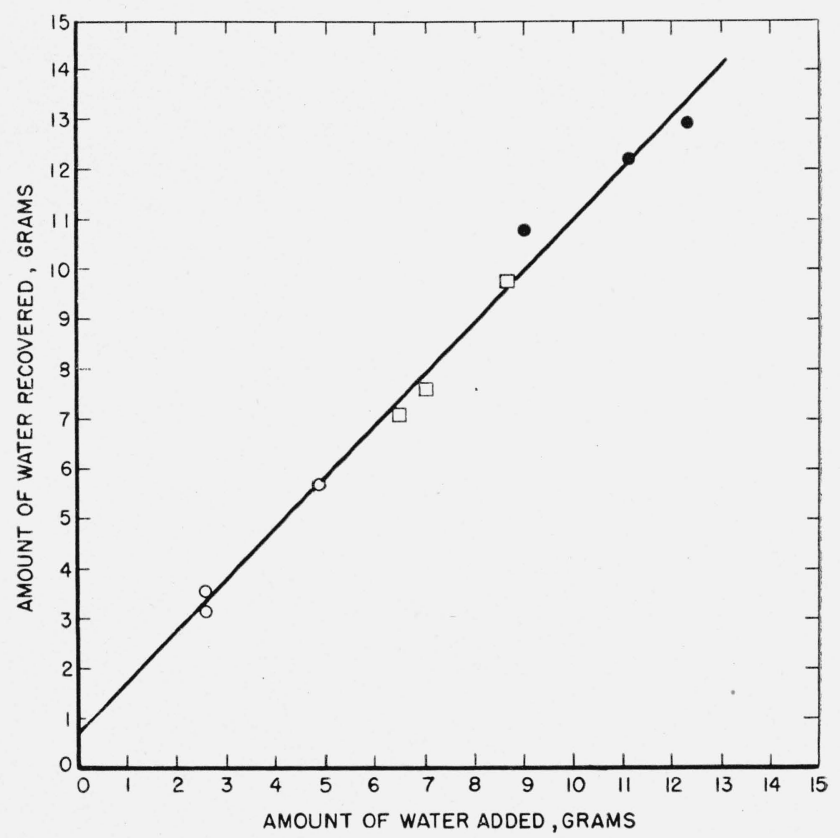

FIGURE 2. Amount of water recovered versus the amount of water added for untreated drum toluene used directly.

o, 45-min distillation; $\square, 90$-min distillation; cept, $0.070 \mathrm{~g}$; slope, 1.03 .

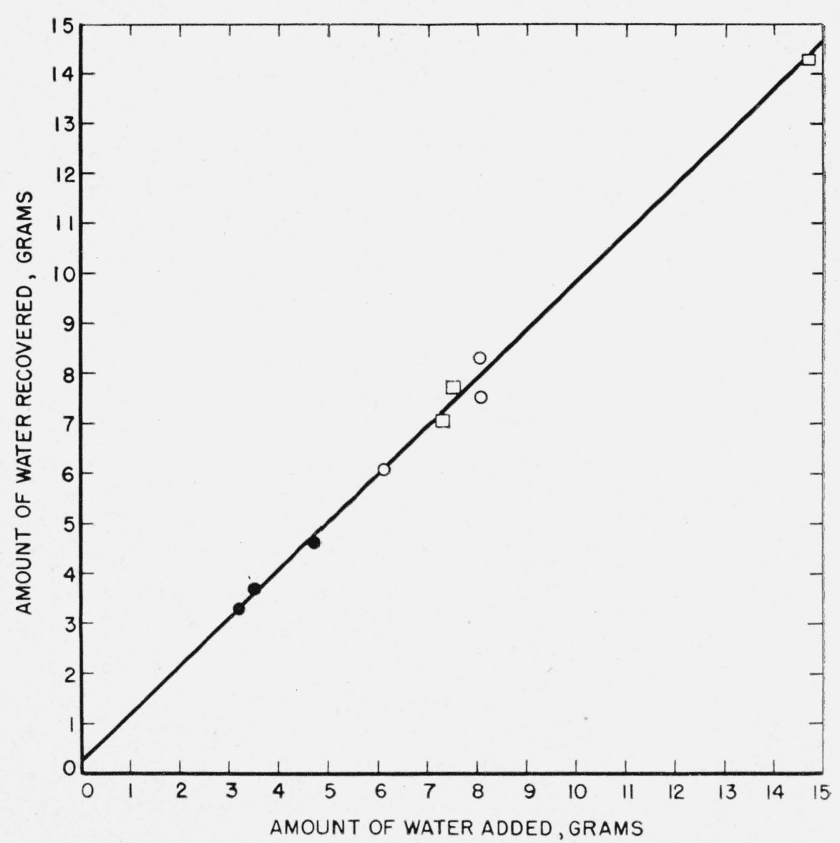

Figure 3. Amount of water recovered versus amount of water added for drum toluene filtered through a 1/1/2-ft column of activated silica gel.

,45-min distillation; $\square, 90$-min distillation cept, $0.028 \mathrm{~g}$; slope, 0.957 . 


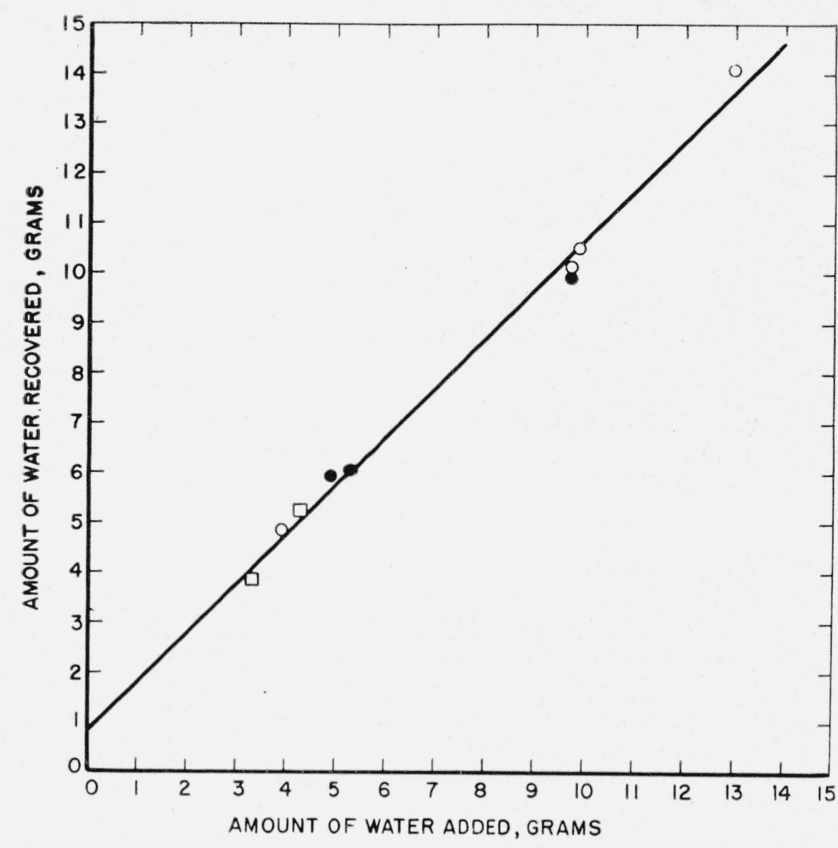

Figure 4. Amount of water recovered versus the amount of water added for drum toluene distilled and the wet forerun removed.

$\bigcirc$, 45-min distillation; $\square, 90-\mathrm{min}$ distillation; cept, $0.085 \mathrm{~g}$; slope, 0.986 .

the recovery and correction for water in each of the toluenes listed in table 1 . The toluene treated with silica gel showed a recovery significantly less than 100 percent but also showed no significant water correction for the toluene. That the other toluenes did not show a significant difference from 100-percent recovery is probably due to the lower precision in these cases. However, the water correction was appreciable for these two toluenes. Further, the toluene treated with silica gel gave the lowest standard deviation of the three toluenes.

TABLE 1. Standard deviation, water correction, and recovery as affected by treatment of the toluene

\begin{tabular}{|c|c|c|c|c|c|c|}
\hline & \multicolumn{2}{|c|}{$\begin{array}{l}\text { Toluene passed } \\
\text { through silica gel }\end{array}$} & \multicolumn{2}{|c|}{ Distilled toluene } & \multicolumn{2}{|c|}{ Untreated toluene } \\
\hline & $\begin{array}{l}\text { Weight of } \\
\text { water in } \\
\text { rubber }\end{array}$ & $\begin{array}{l}\text { Weight of } \\
\text { water re- } \\
\text { covered }\end{array}$ & $\begin{array}{l}\text { Weight of } \\
\text { water in } \\
\text { rubber }\end{array}$ & $\begin{array}{l}\text { Weight of } \\
\text { water re- } \\
\text { covered }\end{array}$ & $\begin{array}{l}\text { Weight of } \\
\text { water in } \\
\text { rubber }\end{array}$ & $\begin{array}{l}\text { Weight of } \\
\text { water re- } \\
\text { covered }\end{array}$ \\
\hline & $\begin{array}{r}g \\
1.4685 \\
0.4633 \\
.6122 \\
.7511 \\
.3488\end{array}$ & $\begin{array}{r}g \\
1.4339 \\
0.4650 \\
.6058 \\
.7703 \\
.3714\end{array}$ & $\begin{array}{c}g \\
0.9696 \\
1.2866 \\
0.3327 \\
.5250 \\
.4285\end{array}$ & $\begin{array}{r}g \\
0.9888 \\
1.4071 \\
0.3865 \\
.6070 \\
.5234\end{array}$ & $\begin{array}{r}g \\
0.4847 \\
.8672 \\
.9008 \\
.2601 \\
.6991\end{array}$ & $\begin{array}{r}g \\
0.5743 \\
.9748 \\
1.0821 \\
0.3564 \\
.7586\end{array}$ \\
\hline & $\begin{array}{l}.8064 \\
.7289 \\
.3166 \\
.8061\end{array}$ & $\begin{array}{l}.8357 \\
.7053 \\
.3316 \\
.7628\end{array}$ & $\begin{array}{l}.9839 \\
.4896 \\
.9737 \\
.3887\end{array}$ & $\begin{array}{l}1.0488 \\
0.5928 \\
1.0135 \\
0.4878\end{array}$ & $\begin{array}{r}\text { 1. } 2306 \\
0.2598 \\
.6422 \\
\text { 1. } 1101\end{array}$ & $\begin{array}{r}1.2947 \\
0.3159 \\
.7069 \\
1.2188\end{array}$ \\
\hline $\begin{array}{l}\text { Std.dev.a }(\mathrm{g}) \\
\text { Water (blank) } \\
\text { correction_(g) } \\
\text { Recovery }(\%)\end{array}$ & \multicolumn{2}{|c|}{$\begin{aligned} 0.023 \\
.0282 \\
95.66\end{aligned}$} & \multicolumn{2}{|c|}{0.035} & \multicolumn{2}{|c|}{0.040} \\
\hline
\end{tabular}

a Single determination.
Comparisons were also made between this method and those involving the mastication of the samples on hot rolls or oven-drying of thin sheets. The data from such a comparison is shown in table 2 . The weights of sample used for the water determination in the four methods were quite different, ranging from a few grams for the Mill-oven method to $450 \mathrm{~g}$ for the hot-mill method. However, a comparison of the standard deviations of the methods indicates that the distillation method is more precise than either the Goodrich method or the Specification Hot-mill method. The Specification Mill-oven method is more precise than the distillation method, but the operating factors of the mill method are to its disadvantage [12].

TABLE 2. Comparison of methods for the determination of moisture in synthetic rubbers

\begin{tabular}{|c|c|c|}
\hline Method & $\begin{array}{l}\text { Toluene } \\
\text { treatment }\end{array}$ & $\begin{array}{l}\text { Standard devi- } \\
\text { ation of a single } \\
\text { determination } \\
\text { of water }\end{array}$ \\
\hline $\begin{array}{l}\text { Distillation } \\
\text { Specification Mill-oven Method (C-1-c) } \\
\text { [12] } \\
\text { Specification Hot-mill Method (C-1-a) } \\
\text { [12] }\end{array}$ & $\left\{\begin{array}{l}\text { Silica gel } \\
\text { Distilled } \\
\text { Untreated }\end{array}\right.$ & $\begin{array}{c}\text { Percent } \\
0.023 \\
.035 \\
.040 \\
\\
.008 \\
.045 \\
.05\end{array}$ \\
\hline
\end{tabular}

The author is very grateful to Patricia Custer Jackson and Aurelia Arnold for making numerous measurements for the purpose of evaluating the improvements in the apparatus, and also to John Mandel for advice and assistance in designing statistical experiments to show quantitatively the value of the improvements.

\section{References}

[1] E. W. Dean and D. D. Stark, A convenient method for the determination of water in petroleum and other organic emulsions, Ind. Eng. Chem. 12, 486 (1920).

[2] G. L. Bidwell and W. F. Sterling, Preliminary notes on the direct determination of moisture, Ind. Eng. Chem. 17, 147 (1925).

[3] J. A. DeLoureiro, An improved technic in the toluene distillation method for the determination of moisture in foodstuffs, J. Assoc. Official Agr. Chem. 21, 645 (1938).

[4] J. E. Cleland and W. R. Fetzer, Determination of moisture in sugar products, Ind. Eng. Chem. Anal. Ed. 14, 124 (1942).

[5] W. G. Marskell and J. E. Rayner, An improved apparatus for the determination of water in oils and fuels, Fuel 26, 49 (1947)

[6] W. Normann, Zur wasserbestimmung in fetten und anderen stoffen, Z. angew. Chem. 38, 380 (1925).

[7] A. C. Beckel, A. G. Sharp, and R. T. Milner, Apparatus for determining moisture by the distillation method, Ind. Eng. Chem. Anal. Ed. 11, 425 (1939).

[8] E. R. Caley and L. Gordon, Trap for the determination of water by the distillation method, Anal. Chem. 21, 749 (1949).

[9] J. Mitchell and D. M. Smith, Aquametry, pp. 4 to 5 (Interscience Publishers, Inc., New York, N. Y., 1948).

[10] M. Tryon and P. Custer, National Bureau of Standards, unpublished report to Office of Rubber Reserve (May $24,1948)$. 
[11] M. Tryon, P. C. Jackson, and J. Mandel, National Bureau of Standards, unpublished report to Office of Rubber Reserve (Feb. 28, 1949).

[12] P. Custer, National Bureau of Standards, unpublished report to Office of Rubber Reserve (Feb. 6, 1947).

[13] P. C. Baker, B. F. Goodrich Chemical Co., unpublished report to Office of Rubber Reserve (Aug. 20, 1946).
[14] E. G. Rochow, Introduction to the chemistry of the silicones, p. 32 and 83 to 88 (John Wiley and Sons, Inc., New York, N. Y., 1946).

Washington, January 24, 1950.

\title{
Porcelains Within the Beryllia Field of the System Beryllia-Alumina-Zirconia
}

\author{
By Stewart M. Lang, Laurel H. Maxwell, and Milton D. Burdick
}

\begin{abstract}
The general physical properties of practically impervious porcelains within the beryllia $(\mathrm{BeO})$ field of the system beryllia-alumina-zirconia $\left(\mathrm{BeO}-\mathrm{Al}_{2} \mathrm{O}_{3}-\mathrm{ZrO}_{2}\right.$ ), whose base compositions approximate that of NBS Body No. 4811C, were found to be: maturing range, $1,500^{\circ}$ to $1,600^{\circ} \mathrm{C}$; apparent density, 2.9 to $3.4 \mathrm{~g} / \mathrm{cm}^{3}$; shrinkage, 17.8 to 20.5 percent; roomtemperature compressive strength, 238,000 to $305,000 \mathrm{lb} /$ in. $^{2}$; room-temperature transverse strength, 17,200 to $34,100 \mathrm{lb} / \mathrm{in.}^{2}$; room-temperature transverse strength after thermal shocking, 17,800 to $31,900 \mathrm{lb} /$ in. $^{2}$; transverse strength at $1,800^{\circ} \mathrm{F}\left(982^{\circ} \mathrm{C}\right), 15,100$ to 25,100 $\mathrm{lb} /$ in. $^{2}$; approximate Young's modulus at $1,800^{\circ} \mathrm{F}, 28,000,000$ to $38,000,000 \mathrm{lb} / \mathrm{in}^{2}$; relative thermal shock resistance, good; and Knoop hardness numbers (500-g load), 550 to 830 . An admixture of 2 weight percent of calcia $(\mathrm{CaO})$ to the base compositions of these porcelains (without which the specimens would not mature to an impervious structure) caused the appearance of unidentified isotropic phases.
\end{abstract}

\section{Introduction}

Because of the advantageous high-temperature strength characteristics of "glass-free" bodies composed of the ceramic oxides, singly or in combination, as compared to similar strength properties of the metallic alloys, many refractory porcelains may be particularly well adapted for diversified uses in such power-plants as the gas-turbine and jet-propulsion engines.

Previous work at this Bureau $[1,2,3],{ }^{1}$ at the Ohio State University Experiment Station [4], at the University of Illinois [5], and at the Lewis Flight Propulsion Laboratory of the National Adivsory Committee for Aeronautics [6] has shown NBS Body No. 4811C [3], whose composition is within the system beryllia-alumina-zirconia $\left(\mathrm{BeO}-\mathrm{Al}_{2} \mathrm{O}_{3}-\mathrm{ZrO}_{2}\right)$, to be outstanding in many high-temperature properties when compared with other refractory whitewares. Such comparisons made it seem advisable to investigate and report some of the physical properties of porcelains whose compositions approximate that of body $4811 \mathrm{C}$.

A previous report [3] gives in some detail the phase relations of the system $\mathrm{BeO}-\mathrm{Al}_{2} \mathrm{O}_{3}-\mathrm{ZrO}_{2}$. The failure of these oxide bodies to mature to nonporous structures was discussed in the Bureau report, but it was shown that the addition of small quantities of auxiliary fluxes to the base compositions did permit maturing of the bodies to a practically impervious condition. An addition of 4 percent of magensia to body 4811, whose mole composition ratio is 48 $\mathrm{BeO}: 1 \mathrm{Al}_{2} \mathrm{O}_{3}: 1 \mathrm{ZrO}_{2}$, caused the most pronounced

\footnotetext{
${ }_{1}^{1}$ Figures in brackets indicate the literature references at the end of this paper.
}

effect on the maturing range. Experience has shown that the use of magnesia tends to increase the particle sizes or distort the particle shapes and thereby to decrease the body strength. Considering all of the properties studied, an addition of 2 weight percent of calcia $(\mathrm{CaO})$ produced the most satisfactory 4811 bodies, and this particular body composition is correctly designated as Body No. 4811C. All but one of the porcelain compositions given in this report contain a 2-percent addition of calcia to the base composition; the exception, for comparative purposes, is body $4811 \mathrm{M}$, which contains an addition of 4 percent of magnesia.

\section{Materials and Equipment}

The oxides used in the preparation of the test specimens were commercially available materials of high purity. The beryllia ( $\mathrm{BeO})$ was of nominal 99.7-percent purity, and spectrograms showed only traces of copper, iron, and magnesium, and very weak lines of silicon. Ground, washed, and sieved tabular alumina $\left(\mathrm{Al}_{2} \mathrm{O}_{3}\right)$ of 99.5 -percent purity was supplied through the courtesy of the Champion Spark Plug Co. Commercial zirconia $\left(\mathrm{ZrO}_{2}\right)$ of nominal 99-percent purity was recalcined at $1,440^{\circ}$ C, after which spectrograms showed medium lines for niobium (columbium) and titanium, and only very weak lines or traces for calcium, copper, iron, magnesium, lead, and silicon. Calcia $(\mathrm{CaO})$ was added as the pure chemically precipitated carbonate. As prepared for use, the materials were, in all instances, sufficiently finely divided to pass the No. 325 U. S. Standard Sieve. Comminution procedures have been given [7]. 